PENANGANAN KASUS ANAK USIA DINI

MEMENUHI MATA KULIAH BIMBINGAN KONSELING

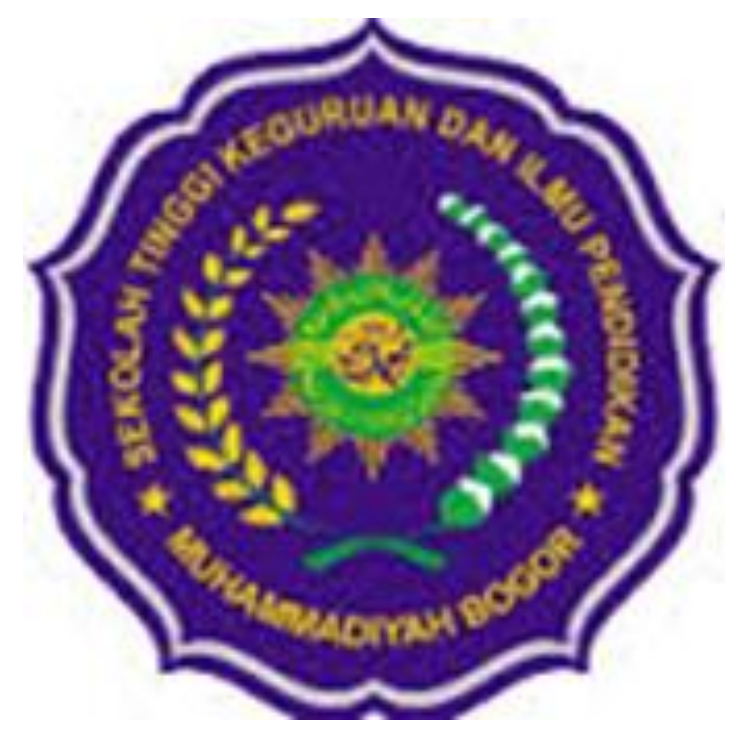

DI SUSUN OLEH:

DEWI MARIYANTI

ELSA RAHMANIS

NIM : 0142S1D018023

NIM : 0142S1D018024

STKIP MUHAMMADIYAH BOGOR

PROGRAM STUDI PENDIDIKAN GURU PAUD

TAHUN AKADEMIK 2019 


\section{PENANGANAN KASUS ANAK USIA DINI DI TPA}

1. Judul pembahasan

Penanganan anak usia dini

2. Tujuan pembelajaran

Mahasiswa dapat memahami permasalahan AUD di tempat penitipan anak.

3. Materi pembelajaran

\section{A. Pengertian TPA}

TPA merupakan salah satu bentuk paud yang pada jalur pendidikan non formal yang menyelenggarakan program pendidikan sekaligus pengasuhan dan kesejahteraan sosial terhadap anak sejak lahir sampai dengan usia 6 tahun.

Tempat penitipan anak atau daycare adalah sarana pengasuhan anak dalam kelompok biasanya di laksanakan pada saat jam kerja. Daycare merupakan upaya yang terorganisasi untuk mengasuh anak-anak di luar rumah mereka selama beberapa jam dalam satu hari bilamana asuhan orangtua kurang dapat di laksanakan secara lengkap. Pengertian daycare hanya sebagai pelengkap terhadap asuhan orangtua dan bukan sebagai pengganti asuhan orangtua (patmonodewo : $2003: 77$ ).

Salah satu jenis pelayanan TPA adalah jenis system fullday, dimana jenis layanan yang memberikan layanan jasa penitipan anak dengan waktu penuh. Melihat dari rentang waktu lamanya anak di titipkan, maka pelayanan lembaga sosial dalam bentuk taman penitipan anak dengan sisitem fullday harus sesuai dengan kebutuhan anak usia dini yang meliputi peningkatan gizi, pengembangan intelektual, emosional dan sosial. Oleh karena itu, perlu di kaji apakah layanan anak usia dini di TPA dengan system fullday memenuhi kebutuhan keluarga dalam rangka membantu orangtua/keluarga dalam memantapkan fungsi keluarga dan fungsi lembaga sebagai sesuai 
dengan peraturan pemerintah serta sebagai wujud usaha kesejahteraan anak yang merupakan tanggung jawab sosial lembaga.

B. Tujuan program layanan TPA :

1. Memberikan layanan kepada anak usia 0-6 tahun yang terpaksa di tinggal orangtua nya karena pekerjaan atau halangan lainnya.

2. Memberikan layanan yang terkait dengan pemenuhan hak-hak anak untuk tumbuh berkembang, mendapat perlindungan dan kasih sayang serta hak untuk partisipasi dalam lingkungannya.

C. Tujuan pengelolaan kegiatan di taman penitipan anak Pengelolaan di TPA anak mempunyai tujuan-tujuan sebagai berikut:

1. Tujuan pengelolaan kegiatan di TPA untuk anak.

a. Dapat mengembangkan kehidupan beragama ( spiritual intelligerce )

b. Dapat mengembangkan kemandirian ( life skill )

c. Dapat mengembangkan kemampuan berbahasa (linguistic intelligence)

d. Dapat mengembangkan daya pikir (logika math intelligence)

e. Dapat mengembangkan daya cipta (visual spasial)

f. Dapat mengembangkan perasaan dan emosi (emotional intellegince)

g. Dapat mengembangkan keterampilan bermasyarakat dan kehidupan kemampuan bersosialisasi (interpersonal)

h. Dapat mengembangkan jasmani dan keterampilan (bodily kinestetic)

i. Dapat mengembangkan pengamatan (naturalis intelligence)

j. Dapat meningkatkan proses tumbuh kembang anak secara wajar

2. Tujuan pengelolaan di TPA untuk orangtua 
- Membantu meningkatkan proses tumbuh kembang anak dalam rangka membentuk sumber daya manusia yang berkualitas.

- Membantu rangka menatapkan fungsi keluarga khususnya dalam meningkatkan pendidikan dan kesejahteraan anak.

3. Tujuan pengelolaan kegiatan TPA untuk masyarakat

a. Memeberikan motivasi kepada masyarakat akan pentingnya pelajaran yang terpadu (kesehatan, gizi, agama, pendidikan) untuk anak dari usia lahir sampai dengan 3 tahun. Hal ini sebagai upaya meletakkan dasardasar perkembangan yang baik pada diri anak sehingga anak dapat mengenal diri dan lingkungannya.

D. Faktor penyebab permasalahan anak

Terdapat beberapa faktor penyebab permasalahan anak,baik yang bersifat intrinsic (berasal dari diri sendiri) maupun ekstrintik (berasal dari luar diri anak). Secara umum faktor-faktor tersebut adalah:

1. Pembawaan, yakni anak dengan semua keadaan yang ada pada dirinya.

2. Lingkungan keluarga, mencangkup pola asuh keluarga terutama orangtua.

3. Lingkungan masyarakat, mencangkup pergaulan, norma, adat istiadat,dan lain-lain.

E. Permasalahan di TPA

1. Sering menangis karna anak masih belum mampu mengungkapkan apa yang mereka inginkan.

Cara menangani : ajak anak bermain agar suasana tidak jenuh

2. Susah makan adalah salah satu masalah yang paling sering di temui pada balita di tempat penitipan anak. 
Cara menangani : ciptakan rutinitas makan yang teratur, jangan memaksa anak makan dengan cepat atau menghabiskan semua makanan di piringnya.

3. Anak lebih agresif atau pemarah karna merasa kurangnya perhatian orangtua nya dirumah.

Cara menangani : petugas tpa harus lebih peka terhadap perasaan anak agar anak merasa di perhatikan.

4. Anak lebih pemarah karna merasa kurangnya kasih sayang dari orang sekitarnya terutama keluarga dan orangtua. Solusinya biarkan anak meluapkan apa yang dia inginkan.

5. Cengeng, anak cengeng ini wajar terlebih ketika berumur 2 tahun biasanya anak masih belum mampu menjelasakan apa yang membuat si anak menangis. Pada dasarnya cengeng bisa disebabkan karena beberapahalumum, salah satunya karena anak memiliki perasaan yang sensitive. Solusinya adalah bantu perkembangan kecerdasan emosional anak dengan cara mengajarkan anak agar lebih bisa tenanguntuk mengendalikan emosi.

6. Susah tidur, ada berbagai penyebab anak susah tidur . diantara penyebab anak susah tidur adalah karena faktor keturunan. Faktor lainnya adalah karena kondisi badan anak sedang tidak fit,misalnya saja sedang sakit. Rasa sakit dapat membuat badan menjadi tidak nyaman sehingga anak susah untuk tidur. Solusinya anda harus mengetahui dahulu tentang pola tidur si anak karna beda anak beda pula pola tidurnya. Ada yang ketika berbaring langsung bisa tidur, ada pula yang harus simulasi seperti dongeng, permainan dan sebagainya.

\section{F. KESIMPULAN}

Anak usia dini adalah masa dimana otak anak sedang mengalami perkembangan dengan baik, untuk itu pendidikan sejak usia dini 
sangat penting di berikan karena akan menentukan kualitas anak dari mulai kecil sampai dewasa. Anak usia 0-6 tahun dapat di berikan pendidikan dengan cara memasukannya ke sekolah TPA. Terkadang ada saja kendala yang terjadi ketika pembelajaran, seperti tenaga kependidikan, peserta didik,maupun fasilitas yang belum memadai.

Guru sebaiknya mengetahui permasalahan apa saja yang terjadi beserta dengan cara penanganannya agar ketika masalah itu ada kita sudah mengerti dan tahu apa yang harus kita lakukan.

- Soal pilihan ganda

1. Usia berapa anak mulai di masukan ke TPA .....
a. 0-6 tahun
c. 3-4 tahun
b. 4-5 tahun
d. 5-6 tahun

2. Sebutkan macam-macam permasalah anak di TPA, kecuali .....
a. Sering menangis
c. susah makan
b. Susah tidur
d. asyik bermain

3. Pada usia berapa anak sering menangis ( cengeng) .....
a. 5 tahun
c. 3 tahun
b. 6 tahun
d. 2 tahun

4. Berikut ini adalah tujuan pengelolaan kegiatan di TPA untuk anak, kecuali....
a. Dapat mengembangkan kemandirian
b. Dapat mengembangkan kemampuan berbahasa
c. Dapat mengembangkan kehidupan beragama
d. Dapat membantu meningkatkan proses tumbuh kembang anak dalam rangka membentuk SDM yang berkualitas sejak dini

5. Paud yang di terapkan di program TPA di dasarkan atas prinsip-prinsip, kecuali ....

a. Berorientasi pada kebutuhan anak 

b. Sesuai dengan keunikan individu
c. Kegiatan belajar di lakukan dengan cara monoton
d. Kegiatan belajar di lakukan dengan cara bermain

6. Berikut ini adalah solusi dari penanganan anak susah makan, kecuali....
a. Ciptakan rutinitas makan yang teratur pada anak
b. Memaksa anak agar makan banyak
c. Jangan memaksa anak makan dengan cepat
d. Ciptakan suasana makan yang tenang

7. Dapat mengembangkan kehidupan beragama (spiritual intelligence) termasuk pengelolaan di TPA untuk....
a. Masyarakat
c. orang tua
b. Anak
d. keluarga

8. 1. Berorientasi pada kebutuhan anak

2. kegiatan anak di lakukan melalui bermain

3. anak sebagai pembelajar aktif. Termasuk ke dalam pembahasan apakah kalimat di atas.....

a. Tujuan pengelolaan kegiatan di TPA untuk anak

b. Tujuan pengelolaan kegiatan di TPA untuk orangtua

c. Prinsip-prinsip umum TPA

d. Tujuan pengelolaan kegiatan di TPA untuk masyarkat

9. Membantu dalam perkembangan kecerdasan emosional anak dengan cara mengajarkan anak agar lebih bisa tenang untuk mengendalikan emosinya solusi apakah ini....
a. anak agresif
c. cengeng atau sering menangis
$\mathrm{b}$ anaak pemarah
d. anak susah makan

10. Membiarkan anak meluapkan apa yang di inginkan solusi apakah ini ....
a. anak pemarah
c. anak susah makan
b. anak cengeng
d. anak susah tidur 
- KUNCI JAWABAN

1. A. 0-6 tahun

2. D. Asyik bermain

3. D. 2 tahun

4. D. Dapat membantu meningkatkan proses tumbuh kembang anak dalam rangka membentuk SDM yang berkualitas sejak dini

5. C. Kegiatan belajar di lakukan dengan cara monoton

6. B. Memaksa anak agar makan banyak

7. B. Anak

8. C. Prinsip-prinsip TPA

9. C. Cengeng atau sering menangis

10. A. Anak pemarah

- ESAY

1. Apa tujuan layanan di TPA ?

Kunci jawaban :

Tujuan layanan di TPA adalah :

A. Memberikan layanan kepada anak usia 0-6 tahun yang terpaksa di tinggal orangtua karena pekerjaan.

B. Memberikan layanan yang terkait dengan pemenuhan hak-hak anak untuk tumbuh dan berkembang.

2. Mengapa anak yang di titipkan di TPA lebih agresif?

Kunci jawaban :

Anak-anak yang di titipkan di TPA lebih agresif karena merasa kurangnya perhatian dari orangtua.

3. Apa tujuan pengelolaan kegiatan di TPA untuk masyarakat ?

Kunci jawaban :

Tujuan pengelolaan kegiatan TPA untuk masyarakat yaitu untuk memberikan motivasi kepada masyarakat akan pentingnya pelajaran yang terpadu untuk anak dari usia lahir sampai dengan 3 tahun. 
4. Permasalahan apa saja yang sering muncul di TPA ?

Kunci jawaban :
a. Anak sering menangis
b. Anak susah makan
c. Anak lebih agresif

5. Sebutkan macam-macam prinsip umum di TPA ?

Kunci jawaban :
a. Berorientasi pada kebutuhan anak
b. Sesuai dengan perkembangan anak
c. Kegiatan belajar di lakukan melalui bermain 


\section{DAFTAR PUSTAKA}

Arsyad, Arsyad, \& Sulfemi, Wahyu Bagja. (2016). Pengembangan Keprofesian Berkelanjutan (PKB) Bagi Guru Melalui Program Induksi Guru Pemula (PIGP). Seminar Nasional STKIP Muhammadiyah Bogor.2 (2), 12-22.

Arsyad, Arsyad, \& Sulfemi, Wahyu Bagja. (2013). Pengaruh Persepsi Guru Tentang Kemampuan Manajerial Kepala Sekolah dan Kecerdasan Emosional Guru Terhadap Kinerja Guru (Studi Kasus Di SMK Muhammadiyah 6 Kabupaten Bogor). Fascho 2 (1), 1-9

Depdiknas, 2009. Permendiknas No. 58 tahun 2009 tentang standar pendidikan Anak Usia Dini. Jakarta:2009.

Patmonodewo soemarti, (2003). Pendidikan anak pra sekolah, jakarta : PT. Rineka cipta www.kompasiana.com http://attalarikfathoriq.blogspot.co.id/2009?/masalah-anak-dalam-pengelolaankelas.html

Sudirman, Sudirman \& Sulfemi, Wahyu Bagja. (2010). Korelasi Antara Konsep Diri Guru dengan Profesionalisme Guru di SMA Negeri 1 Pamijahan Kabupaten Bogor. Edutecno 2 (2), 10-19

Sulfemi, Wahyu Bagja. (2016). Kompetensi Profesionalisme Guru Indonesia dalam Menghadapi MEA. Prosiding Seminar Nasional STKIP Muhammadiyah Bogor. 1 (1), 62-77.

Sulfemi, Wahyu Bagja. (2016). Perundang-Undangan Pendidikan. Bogor : Program Studi Administrasi Pendidikan STKIP Muhammadiyah Bogor.

Sulfemi, Wahyu Bagja. (2016). Modul Pembelajaran Ilmu Sosial dan Budaya Dasar. Bogor : STKIP Muhammadiyah Bogor.

Sulfemi, Wahyu Bagja. (2018). Manajemen Kurikulum di Sekolah. Bogor : Visi Nusantara Maju.

Sulfemi, Wahyu Bagja dan Desmiati, Zulaicha. (2018). Model Pembelajaran Missouri Mathematics Project Berbantu Media Relief Experience dalam Meningkatkan Hasil Belajar Siswa. Jurnal Pendas Mahakam . 3 (3), 232245 .

Sulfemi, Wahyu Bagja. (2019). Asosiatif Layanan Tenaga Perpustakaan Sekolah Dengan Motivasi Membaca Siswa di Kabupaten Bogor. Edutecno. 19 (2), $1-10$.

Sulfemi, Wahyu Bagja. (2019). Manajemen Pendidikan Multi Kultur. Bogor : STKIP Muhammadiyah Bogor

Sulfemi, Wahyu Bagja. (2019). Manajemen Pendidikan Berbasis Multi Budaya. Bogor : STKIP Muhammadiyah Bogor 
Sulfemi, Wahyu Bagja dan Mayasari, Nova. (2019). Peranan Model Pembelajaran Value Clarification Technique Berbantuan Media Audio Visual Untuk Meningkatkan Hasil Belajar IPS. Jurnal Pendidikan. 20. (1). 53-68.

Sulfemi, Wahyu Bagja., \& Yuliana, Desi. (2019). Penerapan Model Pembelajaran Discovery Learning Meningkatkan Motivasi dan Hasil Belajar Pendidikan Kewarganegaraan. Jurnal Rontal Keilmuan Pancasila dan Kewarganegaraan 5 (1), 17-30

Yusfiriadi, Yusfiriadi, \& Sulfemi, Wahyu Bagja. (2011). Pemberdayaan Unit Produksi Melalui Pendekatan Manajemen Stratejik di SMK Pertiwi Kabupaten Bogor. Edutecno 3 (1), 1-10

Yusfiriadi, Yusfiriadi, \& Sulfemi, Wahyu Bagja. (2012). Penyelewangan Dana Dalam Dunia Pendidikan. Fascho 1 (1), 1-9. 